\title{
Nuance democrática
}

\author{
Cristina de Souza Agostini. \\ Orientador: Roberto Bolzani Filho \\ FAPESP
}

\begin{abstract}
"Porque influenciar uma pessoa é emprestar-lhe a nossa alma. Essa pessoa deixa de ter idéias próprias, de vibrar com as suas paixões naturais. As suas qualidades não são verdadeiras. Os seus pecados, se é que existe o que se chama pecado, vêm-lhe de outrem. Essa pessoa torna-se o eco da música de outra pessoa, intérprete de um papel que não foi escrito para ela. A finalidade da vida é para cada um de nós o aperfeiçoamento, a realização plena de nossa personalidade. Hoje, cada qual tem medo de si próprio; esquece o maior dos deveres: o dever que tem para consigo mesmo." (Oscar Wilde. O retrato de Dorian Gray)
\end{abstract}

Pretendo apresentar o diagnóstico de Sócrates acerca do regime democrático ao longo da República de Platão. A partir daí e após uma breve distinção entre democracia antiga e democracia moderna -para não incorrermos em anacronismos -, tentarei nuançar como, apesar das diferenças existentes entre a Antigüidade e nossa "modernidade", entre a cidade grega e o Brasil e entre Platão e nós, a crítica do filósofo à sua sociedade ainda nos dá instrumentos para pensarmos acerca de nossa política contemporânea. Como os escritos do pensador grego são capazes de motivar questionamentos sobre uma 
(des) organização tão distante cronologicamente da sua, ou seja, sobre a sociedade moderna.

A República de Platão, juntamente com a Política de Aristóteles, mais do que uma descrição sobre a vida política na Grécia Antiga ou conselhos para uma boa administração, contém análises críticas que se propõem a alcançar o fundamento da relação da pólis com seus indivíduos.

Encontra-se delineado por Sócrates, na República, um modelo ideal político constituído por cidadãos felizes e justos, no qual quem ocupa o cargo supremo das decisões referentes à cidade e à vida de seus habitantes é aquele que por justiça exerce tal função. Esse modelo tem como suporte a noção de que uma vida feliz reside em se fazer aquilo para que, por natureza, cada um está apto. Desse modo, justiça significa seguir a inclinação natural: é-se justo ao fazer aquilo para o qual naturalmente se é dotado.

Entretanto, a natureza necessita de aperfeiçoamento, através de instrumentos pertinentes que retoquem as disposições dos indivíduos. O marceneiro deve aprender a tirar medidas, cortar madeira, lixar, envernizar; enfim, todo o aparato necessário para o fabrico dos artigos de sua profissão. Ele não nasce com a régua e a serra nas mãos; porém, dispõe de maior capacidade para o aprendizado e conseqüente exercício no ramo da carpintaria. De outro modo, o mesmo acontece com o sapateiro, o cozinheiro, o artesão e todas as outras atividades. A cidade ideal prescreve cidadãos felizes porque são justos, ou seja, seguem a máxima "a cada um o que lhe é devido"

Assim, percebemos mais claramente o que antes foi dito sobre o chefe da cidade platônica. Este ocupa o posto supremo das decisões sobre os rumos da pólis, porque é naturalmente dotado para isso. E vai além: ele dedica a vida ao conhecimento do belo e do bom, preocupase em atingir a verdade para o estabelecimento das leis, coloca acima de sua figura o bem-estar da comunidade em que é rei. Tem como parâmetro de decisão um mundo no qual não há possibilidade nem variação: há somente perfeição. Pupilos com tal tutor são os mais fe- 
lizes, pois as decisões que influenciam suas vidas são tomadas tendo em vista apenas o acerto: o risco de falha é mínimo.

Todavia, esse tutor precisa de muito estudo e disciplina. Tem a dialéctica como caminho que permite ascender à verdade imutável de cada ser, equilibra música e ginástica na justa medida, para que alma e corpo convivam harmoniosamente.

O indivíduo em questão, o melhor dentre todos, como se sabe, é o filósofo:

Enquanto não forem, ou os filósofos reis nas cidades, ou os que agora se chamam reis e soberanos filósofos genuínos e capazes (...) não haverá tréguas dos males (...). Efetivamente, é penoso ver que não há outra felicidade possível, particular ou pública. ${ }^{1}$

Desse modo, traça-se a única saída para uma política não degradada: a monarquia ou aristocracia filosóficas, ou seja, ao longo do diálogo platônico compreende-se que um regime virtuoso necessariamente tem como chefe supremo um ou mais filósofos e o que está fora disso, na mesma medida de necessidade, é corrupto, degenerado e prestes a tornar-se algo pior.

Trilhando o caminho dessa argumentação, não precisaremos chegar ao livro VIII da República, no qual as degradações políticas são centrais, para constatarmos a visão negativa lançada sobre a democracia por Platão. O regime democrático é aquele em que o poder de decisão política encontra-se nas mãos do povo. Todos os cidadãos que se reúnem em assembléia podem opinar e votar. A inclinação e conseqüente aprendizado da ciência política por meio de árduo estudo, dedicação e, além disso, que esse estudo só possa ser feito por aqueles naturalmente dotados para o encaixe político: tais idéias não encontram lugar na democracia. Nela, quando se trata de questões referentes à pólis, todos os cidadãos possuem virtude para participar das discussões. As diferenças materiais, de status ou nome desaparecem e

1 PLATÃO. A República (473d). 
dão lugar à igual medida de opiniões. A democracia exclui a idéia de um saber político restrito a poucos, ao contrário, assevera "que não é arte que se aprenda" 2

O livro VI da República, no qual a distinção entre sofista e filósofo é traçada, serve para pensarmos no papel que saberes como a retórica e a sofística exercem na educação da cidade democrática e como são, por conseqüência, incompatíveis com a cidade ideal.

O sofista é a figurinha carimbada dos diálogos platônicos. Ora aparece como "particular mercenário", ora como "caçador de jovens ricos" É aquele que cobra pelo ensino das doutrinas da maioria, chamando a isso ciência. ${ }^{3}$ A personagem do sofista não tem como propósito procurar ou ensinar a verdade. Sua ministração consiste em incutir a capacidade de argumentação sobre qualquer assunto, sem o necessário conhecimento para tal, através dos instrumentos de retórica. Seus alunos buscam a arte da persuasão, sem que isso implique verdade ou falsidade. Num mundo contingente como o democrático, no qual as escolhas feitas hoje podem ser rejeitadas amanhã, o discurso deve dar conta de persuadir o auditório sobre o que, no momento, aparece como a melhor decisão a ser abraçada. O sofista é aquele que move o páthos dos ouvintes, emociona-os. $\mathrm{Na}$ mesma proporção em que é capaz de fazê-los sentir-se no apogeu da existência, ao contrário, consegue que se detestem e reneguem o dia em que nasceram.

Entretanto, para que atinja esse resultado, ele precisa ter o conhecimento de seu público, e a metáfora do grande animal em 493b serve para explicar como isso acontece:

É como se uma pessoa, que tenha de criar um animal grande e forte, aprendesse a conhecer suas fúrias e desejos, por onde tocá-lo, e quando é mais intratável ou mais meigo, e porquê, e cada um dos sons que costuma emitir a propósito de cada coisa, e com que vozes dos outros se amansa ou irrita...

2 PLATÃO. A República (488b).
3 PLATÃO. A República (493a). 
Nesse sentido, o sofista deve sempre estar junto à multidão para observar e cativar. Ele é o "amigo-adorador" das massas e visa ensinar o compêndio da sua própria convivência com elas. A educação empreendida por essa personagem e a posição que ela ocupa na democracia apresenta extrema pertinência a esse regime que, tendo como cerne a participação popular, necessita de várias vozes. Para que as decisões sejam tomadas de maneira ponderada, é preciso que haja o convencimento das massas acerca da utilidade ou inutilidade de determinada proposta apresentada durante as assembléias. É preciso que os cidadãos entrem em acordo por meio do voto, mas antes precisam refletir sobre a escolha a ser feita, o que ocorre por meio da confrontação de argumentos que se dispõem a defender as partes em questão. Daí, então, o papel fundamental da retórica na democracia: ela mostra os dois lados possíveis para uma decisão que, contudo, só poderá ter sua eficácia constatada após a implementação.

Portanto, percebemos o estatuto vampírico que sofista e sua bagagem retórica ocupam na política, segundo Platão. A personagem que, como vimos, apresenta relevância na democracia, por outro lado, não se coaduna com termos como justiça, educação e felicidade; justamente porque tais termos são impensáveis no regime democrático. Já que o sofista legitima essa forma política corrupta, por conseqüência é tão degradado quanto ela. Além disso, utiliza-se do discurso em que a cadência das palavras está à mercê da vontade do orador, ou seja, é retórico, diferentemente do modelo argumentativo platônico, a dialéctica, em que as palavras não se submetem à vontade particular, mas somente à verdade una e imutável. Logo, o sofista e seu objeto de ensino não encontram lugar na cidade em que o filósofo é rei, pois esta não é democrática.

O livro VIII da República, como anteriormente dito, analisa as transformações políticas e, conseqüentemente, as degenerações:

a democracia surge, penso eu, quando após a vitória dos pobres, estes matam uns, expulsam outros, e partilham igualmente com os que restam o governo e as magistraturas, e esses cargos são, na maior parte, tirados à sorte. 
Em 557 a, o regime do povo aparece como aquele em que os pobres são vitoriosos e os ricos perdedores. A cidade democrática apresenta divisão: constituída por ricos e pobres, deixa de ser uma para tornar-se duas. Assim, o livro VIII assume grande importância aqui, pois nele podemos ver como os termos anteriormente arrolados: "justiça, educação e felicidade", excluem-se mutuamente do regime democrático e por que, necessariamente, este deve ser censurado por Platão.

$\mathrm{Na}$ aristocracia filosófica tudo se passa de maneira ordenada e necessária. Em função da metafísica, exposta no livro VII da Repúbli$c a$, chega-se à conclusão de que o único indivíduo que tem o dever de assumir o comando da cidade é o filósofo. A necessidade dessa afirmação apóia-se na noção de justiça: para que o cidadão a exerça, necessita dedicar-se àquilo para o qual naturalmente foi dotado. Por meio da educação filosófica, o chefe seguirá sua natureza e, desse modo, será justo, proporcionando a felicidade da pólis. Uma comunidade sem fragmentação, na qual não existem ricos ou pobres, mas sim, pessoas felizes e irmanadas que não fazem o que têm vontade, mas aquilo para que suas capacidades naturais se prestam. Desse modo, encontramos unidade e necessidade na cidade platônica. Nada se passa por acaso, nem decorre de qualquer desejo contingente: a metafísica deve legitimar a política que, por sua vez, salva a cidade por meio da filosofia. Há felicidade porque há justiça e conseqüentemente educação -no sentido platônico do termo. Não se pensa nesses conceitos de forma isolada: cada um engendra o outro com ordem e necessidade. Sem justiça, não há felicidade; sem educação, não há justiça.

A cidade democrática "estará cheia de liberdade e do direito de falar" e "onde houver tal licença, é evidente que aí cada um poderá dar à sua própria vida a organização que quiser, aquela que lhe aprouver" 4 Portanto, o molde democrata mostra-se desprovido de

${ }^{4}$ PLATÃO. A República (557b). 
qualquer ordem ou necessidade; baseia-se na indeterminaçāo, desordem e bagunça. Tal cidade não pode ser justa: cada qual, ao fazer o que lhe dá na telha, renega a natureza para a qual realmente apresenta aptidão e, por conseguinte, abre mão do bem-estar e da salvação. Assim, o desmonte da cidadela do povo feita pelo filósofo antigo assume perfeita coerência com sua doutrina e seu modelo de pólis.

Contudo, a bomba arremessada sobre esse regime corrompido tem poder de destruição de maior alcance. Em 557c, Sócrates compara às crianças e mulheres as pessoas entusiasmadas com a democracia. $\mathrm{Ou}$ seja, aqueles que julgam tal espécie de governo como a mais bela, não passam de débeis. Tanto as crianças quanto as mulheres não sabem tomar conta de si próprias, muito menos têm idéia do que seja melhor para a condução de uma cidade. (Não por acaso, ambas não participam das assembléias democráticas, já que não possuem o estatuto de cidadania). Enquanto os pequenos necessitam dos pais para tomarem as decisões por eles, as mulheres necessitam de seus maridos. Assim, os democratas, por não saberem dar rumo adequado a sua existência, porque não têm vaga idéia do verdadeiro bem, sentem-se embevecidos com o "manto de muitas cores, matizado com toda espécie de tonalidades" que é a constituição democrática. Constituição esta em que "o fato de não haver necessidade alguma de mandar neste Estado, ainda que se seja capaz de o fazer, nem de ser mandado, se não se quiser, nem de combater, quando os outro combatem, nem de estar em paz, quando os outros estão, se não se desejar a paz; nem, além disso, ainda que alguma lei impeça que se seja governante ou juiz, se deixe de governar e julgar...", aparece divina e deliciosa a quem experimenta. A sensação de liberdade no que concerne ao caminho que cada um pode seguir e as resoluções que irá tomar é peça-chave na democracia. Por meio desse sentimento, ela seduz aqueles que não comandam suas ações e paixões, sugerindo-lhes que, ao contrário, fazem-no muito bem.

${ }^{5}$ PLATÃO. A República (557c). 
Em meio a tamanha liberdade, os cidadãos vagueiam despercebidos pela cidade. Não se importam uns com os outros, pois a satisfação de seus prazeres adquiriu maior relevância que a vida pública. Além disso, no que se refere à vida política, não fazem conta da preparação com que se vai para tal carreira e "só prestam honras a quem proclamar simplesmente que é amigo do povo" " A democracia joga no esgoto a dedicação, a educação e o conhecimento políticos ao enunciar que para se ter parte no governo não se precisa de uma "natureza extraordinária", muito menos do aperfeiçoamento de tal natureza.

Uma situação em que todos os componentes de justiça, felicidade e educação são abortados em prol da lisonja das massas, para que tenham suas vontades satisfeitas, não passa de um modo caprichoso e instável de governo. Ao gabar-se da isonomia com que trata seus habitantes, só reforça sua falta de razão: ela "reparte a sua igualdade do mesmo modo pelo que é igual e pelo que é desigual", ou seja, não é justa, pois não distribui o quinhão devido a cada um segundo o que a natureza prescreveu. É o regime da confusão dos seus atributos, "designando a insolência por boa educação, a anarquia por liberdade, a prodigalidade por generosidade" 7 Até aquilo por que mais se elogia não tem elogio, porque não faz parte de si. Uma tal modalidade "aprazível, anárquica e variegada"8 não significa que seja livre, muito menos feliz.

Ao invés de unir as pessoas, a democracia proporciona o inverso. Tendo o cidadão tamanha falta de governo para fazer o que bem lhe aprouver sem tecer demais considerações acerca do Estado em que vive, privilegia sua "vida privada" em relação aos assuntos da pólis. Talvez a maior crítica que o livro VIII faça à democracia seja aquela em que torna "a mais bela das constituições" no ponto alto da antipolítica. Enquanto o modelo ideal platônico conta com uma co-

6 PLATÃO. A República (558b).

7 PLATÃO. A República (560e).

${ }^{8}$ PLATÃO. A República (558c). 
munidade de mulheres, crianças e, principalmente, de felicidade; enquanto a figura particular dos indivíduos se apaga para fazer prevalecer os interesses do Estado, isto é, da população constituinte da cidade, o regime que entrega o cetro ao povo coloca uns contra os outros. Pensando estarem no mesmo patamar para a proposta ou aprovação de leis, rivalizam porque todos acreditam ter "razão" O papel primordial da política, aproximar as pessoas para a formação de um Estado no qual não haja privilégios nem rixas para o alcance da suprema felicidade, vira pó nos pés democratas. Eles são a despolitização, o caminhar para trás de qualquer Estado, pois afastam os indivíduos do bem-comum para dar vazão às particularidades.

Um estado fragmentado como o democrático não faz nada além de espelhar o cidadão que ele abriga. Este, por sua vez, "passará cada dia a satisfazer o desejo que calhar, umas vezes embriagando-se e ouvindo tocar flauta, outras bebendo água e emagrecendo, outras ainda fazendo ginástica; ora entregando-se à ociosidade e sem querer saber de nada, ora parecendo dedicar-se à filosofia. Muitas vezes entra na política, salta para a tribuna e diz e faz o que adregar. Um dia inveja os militares, e vai para esse lado, ou os negociantes, e volta-se para aí. Na vida dele não há ordem nem necessidade; considera que uma vida desta é doce, livre e bem-aventurada, e segue-a para sempre" ${ }^{9}$ Portanto, assim como a cidade amante da igualdade contém em si todos os dégradés possíveis de todas as constituições, do mesmo modo como é impossível falar em unidade quando esta cidade está em pauta, a alma do homem pertencente a esse habitat não é uma. "Ele é o homem belo e furta-cores", 10 um "mix" de todas as atividades, desejos e prazeres. Não comporta em si um indivíduo, mas todos que couberem. Se a cidade em que vive é esparsa e múltipla, isso resulta de sua alma que, também assim é. A crítica platônica põe o dedo na ferida e até hoje nos dá muito a refletir sobre nossa sociedade democrática atual.

9 PLATÃO. A República (561d/e).

${ }^{10}$ PLATÃO. A República (561e). 
Contudo, para tomarmos o filósofo antigo como referência para nossas indagações contemporâneas, é necessário levarmos em conta que muita coisa mudou ao longo da história das instituições democráticas. Se eu me dispusesse a investigar a fundo tais mudanças, fugiria completamente à proposta de minha pesquisa e, por isso, me contentarei em expor um nuance distintivo entre democracia antiga e democracia moderna, para que a argumentação seja pertinente.

A democracia antiga era direta, o que equivale a dizer que todos os cidadãos tinham direito à participação nas assembléias, dando suas opiniões e votando. As mulheres, escravos, estrangeiros e crianças estavam excluídos, pois não possuíam cidadania. A democracia ateniense pressupõe cidadãos no mesmo patamar quando o que está em jogo é a pólis. Não há saber específico na política e, então, qualquer um está em condições de ser sorteado para quaisquer atividades.

Nossa democracia é representativa, ou seja, delegamos o poder de decisão àqueles que escolhemos mediante o voto e que devem aprovar, vetar ou apresentar leis, segundo "desejaríamos" É uma forma de governo em que "o poder emana do povo" para selecionar aqueles que ocuparão os cargos do executivo e legislativo conforme o que julgamos melhor.

Apesar destas democracias tão longínquas temporalmente e diferentes na estrutura, a crítica platônica à sua democracia nos dá muito a pensar sobre a nossa e não precisamos ir muito longe para isso. Basta olharmos ao nosso redor: o desinteresse generalizado com a política atual. Enquanto muitos consideram um fardo ter de votar, outros votam no "uni-duni-tê" e ainda alguns não sabem para que serve a política.

As relações entre os indivíduos são impessoais, no sentido em que o envolvimento com o outro em determinados âmbitos separa indelevelmente vida pública e privada. Cada qual tem sua vida particular e não admite a intromissão de outrem. Não há bem comum, mas, ao contrário, a busca pela satisfação dos prazeres pessoais e o direito a isso é freqüente na vida democrática. 
Acrescenta-se a esse fato a velha noção do comando popular que deu as caras no discurso de posse de nosso presidente Lula: "Estaremos atentos para que essas negociações (...) não criem restrições inaceitáveis ao direito soberano do povo brasileiro de decidir sobre seu modelo de desenvolvimento" Quem continua a pilotar o navio é a multidão na mesma medida em que esta ainda deve ser agradada: "De pouco valerá participarmos de esforço tão amplo e em tantas frentes se daí não decorrerem benefícios diretos para o nosso povo"; e também elogiada, já que "Este é o país do novo milênio, pela sua potência agrícola (...), mas sobretudo pelos dons e poderes do seu povo" Não por acaso a frase final desse discurso encerra um misto de bajulação, retórica e amizade ao dono da nau: "Viva o povo brasileiro" Entretanto, poderíamos esperar algo diferente em outro molde de governo, ou seja, um discurso no qual o povo não figurasse ser o centro das atenções? Além disso, qual o sentido em atribuir à democracia a busca pela satisfação dos prazeres pessoais e o desinteresse pela política na sociedade moderna? Será isso exclusividade de um determinado regime?

Talvez devamos nos questionar se o espaço que a vida pública ocupa em nossa vida pode ser, de alguma maneira, comparado ao que outrora era para os gregos; levando em conta, o tamanho de nosso mundo em relação ao deles.

Contudo, ainda há possibilidade de uma verdadeira participação política na democracia? Será que existe um modo de tecermos uma crítica à nossa estrutura de poder e mesmo assim continuarmos a ser democratas? Talvez seja em decorrência disso que nosso regime efetivamente se faça: em nossa reflexão, argumentação e questionamentos. Se ele nos dá oportunidade para isso, para pensarmos criticamente sobre ele, nós que não temos metafísica, quem sabe não possamos algum dia aperfeiçoá-lo, lapidá-lo, matizá-lo com os mais lindos tons, tendo como paradigma os mínimos detalhes de nossa vida política? 


\section{Bibliografia}

CHAUI, M. Introdução à história da filosofia. Dos pré-socráticos a Aristóteles, v. I. São Paulo: Companhia das Letras, 2002.

FINLEY, M. Democracia antiga e moderna. Trad. Sandra Bedran e Waldea Barcellos. Rio de Janeiro: Graal, 1988.

. Política. In: Moses Finley (Org.). O legado da Grécia: uma nova avaliação. Trad. Yvette Vieira Pinto de Almeida.Universidade de Brasília, 1998.

PLATÃO. A República. Trad. Maria Helena da Rocha Pereira. Lisboa: Fundação Calouste Gulbenkian, 1987.

WILDE, O. O Retrato de Dorian Gray. Trad. Marina Guaspari. São Paulo: Publifolha, 1998. 